\title{
Logistic Symbiotic Dynamic Model for Producer Services and Manufacturing Industry
}

\author{
Bohui Pang* \\ Dongwu Business School, Soochow University, Suzhou, Jiangsu, China 215021 \\ *bhpang@suda.edu.cn
}

\begin{abstract}
A Logistic symbiotic dynamic model is proposed to describe accurately the symbiotic evolution process for producer services and manufacturing industry. The symbiotic evolutionary process of producer services and manufacturing industry is analyzed practically. The results show that the actual growth rate of each symbiotic units is affected by the number of their own populations and the number of another symbiotic unit. Tendency of symbiotic evolution of producer services and manufacturing displays complex behavior and trajectory. Producer services play a more important role in promoting the development for manufacturing industry and manufacturing industry have a relatively weak effect on producer services.
\end{abstract}

Keywords: producer services; manufacturing industry; symbiosis; evolutionary model.

\section{Introduction}

Interactive development between produce services and manufacturing has become one hotspot research in the world. From the existing literatures, the study on produce services and manufacturing mainly focus on the following aspects. Firstly, many scholars described the interactive relationship between produce services and manufacturing based on the deepening of labor division and the angle of the evolution of industrial structure. Daniels, Zheng Jichang, Chen Xian and Minghua Han analyze the interaction between the producer services and manufacturing from the perspective of the social division of labor and they believe that the industrial division of labor and professional development promotes social economic growth and significantly improves the labor productivity [1,2]. Secondly, the interactive mechanism of producer services and manufacturing is analyzed based on the perspective of the value chain and the value of enterprise is more embodied in external activities $[3,4]$. Thirdly, many scholars from the perspective of knowledge innovation conducted some useful explorations and studied about interactive innovation between knowledge intensive services (KIBS) in producer services and manufacturing [5,6]. Research about the relationship between producer services and manufacturing from the symbiotic perspective is a hotspot in recent years. Kong Deyang and $\mathrm{Xu}$ Xiyan (2008) believed that the manufacturing sub-communities and producer services sub-community were interacting with each other [7]. Hu Xiaopeng (2009) conducted the empirical studies on the relationship between them with the examples of Jiangsu, zhejiang and shanghai, which was based on symbiotic perspective[8]. With the help of symbiotic theory framework, Xu Xuejun $(2008,2011)$ built an empirical model of the symbiotic relationship between producer services and manufacturing $[9,10]$. By constructing symbiotic interactive evolution model of producer services and manufacturing, this article uses Logistic symbiotic evolution model to make a depth study of dynamic process of symbiotic evolution between producer services and manufacturing, and defined interactive stages of producer services and manufacturing and give the specific characteristics. Finally, empirical analysis of the whole evolution of China's producer service industry and manufacturing industry is performed which provides a new theoretical perspective and method for relationships study between producer services and manufacturing.

\section{Logistic Symbiotic Evolution Model of produce services and manufacturing}

Symbiosis includes the three elements which are symbiotic unit, symbiotic environment and symbiotic mode, respectively. In the symbiotic system, producer services and manufacturing 
industries are two symbiotic units. The effect factors and the symbiotic unit make up a symbiotic environment, such as social environment, economic environment and the natural environment. Symbiotic behavior patterns of producer services and manufacturing includes parasitism, commensalism, asymmetrical mutualism and symmetrical mutualism. The symbiotic behavior of symbiotic system of producer services and manufacturing develops from parasitism and commensalism to asymmetrical mutualism, and finally becomes symmetrical mutualism. This process reflects that symbiotic enterprises develop from small to large, and from less to more. It also reflects that development of symbiotic business from inequality to equality symbiosis, and from unstable to stable symbiosis. Development evolution of this symbiotic behavior represents different stages of a symbiotic enterprise in the process of generation and evolution. The largest function of symbiotic behavior development mode of symbiotic enterprise about producer services and manufacturing is profit distribution between symbiotic objects and stability of symbiosis. Although there are a variety of modes, symmetry mutualism is the final goal of evolution. Symmetry mutualism system is the most effective and stable system among all the symbiotic systems. Any system which has a feature of symmetry mutualism has the largest symbiotic energy when they are in the same kind of symbiotic mode. Therefore, the symmetry mutualism is the inevitable direction of symbiotic relationship between producer services and manufacturing.

Development of symbionts is a continuous process. From the perspective of the ecology, the number of producer services and manufacturing population are constrained by the resources, systems and technology, and need to go through development from childhood to adulthood. Based on symbiotic evolution Logistic model, this paper will analyze the dynamic evolution process of the producer services and manufacturing. The Logistic equation can be expressed as follows:

$$
\left\{\begin{array}{l}
\frac{d N(t)}{d t}=r\left[1-\frac{N(t)}{N_{m}}\right] N(t) \\
N\left(t_{0}\right)=N_{0}
\end{array}\right.
$$

Where $N(t)$ is population density in year $t, r$ is the natural growth rate of population, $t_{0}$ is the equation initial value and the value is equal to $0 . N_{0}$ is maximum environmental capacity under the initial conditions and $N_{m}$ is allowed maximum environmental capacity by the natural resources and environment.

Assuming that population densities of producer services and manufacturing are $N_{1}$ and $N_{2}$, the natural growth rates of symbionts are $r_{1}$ and $r_{2}$, and the maximum environmental capacity are $N_{m l}$ and $N_{m 2}$. dynamic evolution equation of producer services and manufacturing population can be expressed as:

$$
\begin{cases}\frac{d N_{1}(t)}{d t}=r_{1}\left[1-\frac{N_{1}(t)}{N_{m 1}}\right] N_{1}(t), & N_{1}\left(t_{0}\right)=N_{10} \\ \frac{d N_{2}(t)}{d t}=r_{2}\left[1-\frac{N_{2}(t)}{N_{m 2}}\right] N_{2}(t), & N_{2}\left(t_{0}\right)=N_{20}\end{cases}
$$

Where, $N_{10}$ and $N_{20}$ respectively represent the initial population densities of produce services and manufacturing industry.

When the two populations interact with each other, it is assumed that the growth rate is influenced interactively by the population number. Considering the symbiotic relationship between manufacturing industry and producer services, the symbiotic dynamic evolution model of two interactive populations can be obtained based on the Logistic equations.

$$
\left\{\begin{array}{l}
\frac{d N_{1}(t)}{d t}=r_{1}\left[1-\frac{N_{1}(t)}{N_{m 1}}++a_{12} \cdot N_{2}(t)\right] N_{1}(t) \\
\frac{d N_{2}(t)}{d t}=r_{2}\left[1-\frac{N_{2}(t)}{N_{m 2}}+a_{21} \cdot N_{1}(t)\right] N_{2}(t)
\end{array}\right.
$$


Where $a_{12}$ is the symbiotic effect coefficient of manufacturing population to producer services population; $a_{21}$ is the symbiotic effect coefficient of producer services population to manufacturing population.

\section{Empirical Analysis of symbiosis model between producer services and manufacturing}

Divide the evolution time into many small periods and take any adjacent two years as the interval $\left[t_{i}, t_{i+1}\right]$. The length of interval is $\Delta t=t_{i+1}-t_{i}=1$. In the evolution curve of the population density, the added value of producer service is $\Delta N_{1}\left(t_{i+1}\right)=N_{1}\left(t_{i+1}\right)-N_{1}\left(t_{i}\right)$ in the interval $\left[t_{i}, t_{i+1}\right]$ and the average is $\bar{N}\left(t_{i+1}\right)=\frac{N_{1}\left(t_{i+1}\right)+N_{1}\left(t_{i}\right)}{2}$. Slope of the line which connects two endpoints of this interval is $\frac{\Delta N_{1}\left(t_{i+1}\right)}{\Delta t}$. Similarly, the added value manufacturing industry output in the interval $\left[t_{i}, t_{i+1}\right]$ is $\Delta N_{2}\left(t_{i+1}\right)=N_{2}\left(t_{i+1}\right)-N_{2}\left(t_{i}\right)$ and the average is $\bar{N}_{2}\left(t_{i+1}\right)=\frac{N_{2}\left(t_{i+1}\right)+N_{2}\left(t_{i}\right)}{2}$. Slope of the line which connects two endpoints of this interval is $\frac{\Delta N_{1}\left(t_{i+1}\right)}{\Delta t}$.

In a small time period, the average of population density at $t_{i}$ and $t_{i+1}$ is used to replace population density of producer services and manufacturing.

$$
\left\{\begin{array}{l}
N_{1}(t)=\bar{N}_{1}\left(t_{i+1}\right) \\
N_{2}(t)=\bar{N}_{2}\left(t_{i+1}\right)
\end{array}\right.
$$

In a small time period $t \in\left[t_{i}, t_{i+1}\right]$, the symbiotic natural the growth rate and the maximum environmental capacity of producer service and manufacturing industries can be approximately expressed as:

$$
\left\{\begin{array}{l}
\lambda_{1}^{i+1}=r_{1}\left[1+a_{12} \cdot \bar{N}_{2}\left(t_{i+1}\right)\right] \\
\lambda_{2}^{i+1}=r_{2}\left[1+a_{21} \cdot \bar{N}_{1}\left(t_{i+1}\right)\right] \\
M_{1}^{i+1}=N_{1}\left[1+a_{12} \cdot \bar{N}_{2}\left(t_{i+1}\right)\right] \\
M_{2}^{i+1}=N_{2}\left[1+a_{21} \cdot \bar{N}_{1}\left(t_{i+1}\right)\right]
\end{array} \quad(i=0,1,2, \cdots, n)\right.
$$

In a small time period $t \in\left[t_{i}, t_{i+1}\right]$, the symbiotic interaction population density of producer service and manufacturing industries is in accordance with Logistic equation and the equation (3) are:

$$
\left\{\begin{array}{l}
N_{1}(t)=\frac{M_{1}^{i+1}}{1+\frac{M_{1}^{i+1}-N_{1}\left(t_{i}\right)}{N_{1}\left(t_{i}\right)} e^{-\lambda_{i}^{++1} \cdot t}} \\
N_{2}(t)=\frac{M_{2}^{i+1}}{1+\frac{M_{2}^{i+1}-N_{2}\left(t_{i}\right)}{N_{2}\left(t_{i}\right)} e^{-\lambda_{2}+\lambda_{2}+t}}
\end{array}\right.
$$

Because the Logistic curve changes of the added value between producer services and manufacturing industries in $\left[t_{i}, t_{i+1}\right]$ are small, the slope of the line connecting two endpoints can approximately replace each point's slope in this interval and the formula (6) becomes as follows:

$$
\left\{\begin{array}{l}
\frac{\Delta N_{1}\left(t_{i+1}\right)}{\Delta t}=\lambda_{1}^{i+1}\left(1-\frac{\bar{N}_{1}\left(t_{i+1}\right)}{M_{1}^{i+1}}\right) \cdot \bar{N}_{1}\left(t_{i+1}\right) \\
\frac{\Delta N_{2}\left(t_{i+1}\right)}{\Delta t}=\lambda_{2}^{i+1}\left(1-\frac{\bar{N}_{2}\left(t_{i+1}\right)}{M_{2}^{i+1}}\right) \cdot \bar{N}_{2}\left(t_{i+1}\right)
\end{array}(i=0,1,2, \cdots, n)\right.
$$

Iterative formulas of the maximum environmental capacity are described as follows: 


$$
\left\{\begin{array}{l}
M_{1}^{i+1}=\frac{\bar{N}_{1}\left(t_{i+1}\right)}{\left.1-\frac{\Delta N_{1}\left(t_{i+1}\right)}{\lambda_{1}^{i+1} \cdot \bar{N}_{1}\left(t_{i+1}\right)}\right)} \\
\left.M_{2}^{i+1}=\frac{\bar{N}_{2}\left(t_{i+1}\right)}{1-\frac{\Delta N_{2}\left(t_{i+1}\right)}{\lambda_{2}^{i+1} \cdot \bar{N}_{2}\left(t_{i+1}\right)}}\right)
\end{array}(i=0,1,2, \cdots, n)\right.
$$

Because $M_{1}^{i+1}>0, \quad 1-\frac{\Delta N_{1}\left(t_{i+1}\right)}{\lambda_{1}^{i+1} \cdot \bar{N}_{1}\left(t_{i+1}\right)}>0$,

$$
\lambda_{1}^{i+1}>\frac{\bar{N}_{1}\left(t_{i+1}\right)}{\Delta N_{1}\left(t_{i+1}\right)} \quad(i=0,1,2, \cdots, n)
$$

$\bar{N}_{1}\left(t_{i+1}\right) 、 \bar{N}_{2}\left(t_{i+1}\right) 、 \Delta N_{1}\left(t_{i+1}\right)$ and $\Delta N_{2}\left(t_{i+1}\right)$ can be calculated by given data. According to the estimated value ( $\hat{\lambda}_{1}^{i+1}$ and $\hat{\lambda}_{2}^{i+1}$ ) of $\lambda_{1}^{i+1}$ and $\lambda_{2}^{i+1}$ within a defined scope, the estimated values $\left(\hat{M}_{1}^{i+1}\right.$ and $\left.\hat{M}_{2}^{i+1}\right)$ of $M_{1}^{i+1}$ and $M_{2}^{i+1}$ can be obtained in each interval $\left[t_{i}, t_{i+1}\right],(i=0,1,2, \cdots, n)$.

After the estimated values of $\hat{\lambda}_{1}^{i+1} 、 \hat{\lambda}_{2}^{i+1} 、 \hat{M}_{1}^{i+1}$ and $\hat{M}_{2}^{i+1}$ are put into the equation (5), the estimated values of $N_{1}\left(t_{i+1}\right)$ and $N_{2}\left(t_{i+1}\right)$ are obtained as follows:

$$
\left\{\begin{array}{l}
\hat{N}_{1}\left(t_{i+1}\right)=\frac{\hat{M}_{1}^{i+1}}{1+\frac{\hat{M}_{1}^{i+1}-N_{1}\left(t_{i}\right)}{N_{1}\left(t_{i}\right)} e^{-\hat{\lambda}_{1}^{++1} \cdot \Delta t}} \\
\hat{N}_{2}\left(t_{i+1}\right)=\frac{\hat{M}_{2}^{i+1}}{1+\frac{\hat{M}_{2}^{i+1}-N_{2}\left(t_{i}\right)}{N_{2}\left(t_{i}\right)} e^{-\hat{\lambda}_{2}^{i+1} \cdot \Delta t}}
\end{array}\right.
$$

Square difference of estimated value at $\mathrm{k}$ times and the actual values of producer services and manufacturing in each year is:

$$
\left\{\begin{array}{l}
\Delta e_{1}^{2}(k)=\sum_{i=0}^{n}\left[\hat{N}_{1}\left(t_{i+1}\right)-N_{1}\left(t_{i+1}\right)\right]^{2} \\
\Delta e_{2}^{2}(k)=\sum_{i=0}^{n}\left[\hat{N}_{2}\left(t_{i+1}\right)-N_{2}\left(t_{i+1}\right)\right]^{2}
\end{array}\right.
$$

Nelder-Mead Simplex algorithm is used to perform continuous iteration until the square difference doesn't decrease or is smaller than the given threshold value. At this time, the value of natural growth rates $\lambda_{1}^{i+1}$ and $\lambda_{2}^{i+1}$ are obtained and the values of maximum environmental capacity in each year will be calculated when the values of natural growth rates are put into Equation (8).

\section{Empirical results Discussion and Analysis}

With the interaction between producer services and manufacturing, the dynamic evolution curve is shown in Figure 1 and Figure 2.

(1) Owing to the symbiotic interaction, the symbiotic environmental capacities of producer services and manufacturing increase gradually and reach 34.567 trillion and 23.676 trillion respectively, which was much higher than the environmental capacities in the independent development mode.

(2) It can be seen from Figure 1 that the added values of the Chinese producer services grow rapidly, which was $32 \%$ of the maximum environmental capacity in 2007 . This demonstrates that producer services is at early rapid growth stage. As shown in Figure 2, the growth rate of manufacturing industry in 1996 slows down and begins to increase rapidly after 2002. In 2007, the population density is $45 \%$ of the largest environmental manufacturing. This implies that manufacturing industry is at the growth stage and doesn't enter the maturity stage.

(3) There exits a symbiotic relationship between producer services and manufacturing. The symbiotic relationship needs to be taken into consideration in the symbiotic relationship model. The segmented symbiotic evolution model can effectively simulate the actual dynamic process of the added values between producer services and manufacturing. Superposition of Logistic curve in 
several consecutive smaller time period can be used to describe accurately the symbiotic dynamic evolution between producer services and manufacturing. The results based on the proposed model are more consistent with the actual situation.

\section{Conclusions}

From the perspective of symbiosis theory, empirical studies about symbiotic evolution of producer services and manufacturing have been conducted. The following conclusions have been obtained.

(1) The model in this paper is applicable to dynamic evolution analysis of the two symbiotic units. The actual growth rate of each symbiotic units is affected by the number of their own populations and the number of another symbiotic unit. The values of natural growth rate and maximum environmental capacity are not constant and change over time.

(2) Tendency of symbiotic evolution of producer services and manufacturing displays complex behavior and trajectory. In the symbiotic mode, the maximum environmental capacity and the natural growth rate between producer services and manufacturing environment changes. Superposition of Logistic curve in several consecutive period can be used to describe symbiotic evolution of Chinese producer services and manufacturing more accurately.

(3) According to the data of producer services and manufacturing from 1983 to 2007, the validation and empirical analysis of model are conducted. The results show that producer service industry in China is at a rapid growth stage and manufacturing is also at growth stage. Both the values of symbiotic interaction coefficients are positive, which imply that the symbiotic model between producer services and manufacturing is asymmetrical mutualism. Producer services makes a large contribution to the development of manufacturing. However the influence that manufacturing plays on producer service is relatively small.

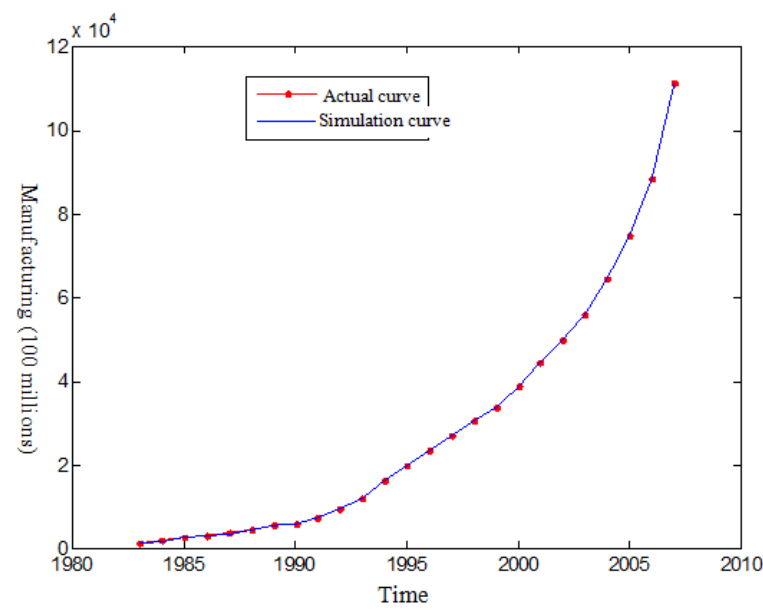

Fig.1 Dynamic evolution curves of Chinese producer services

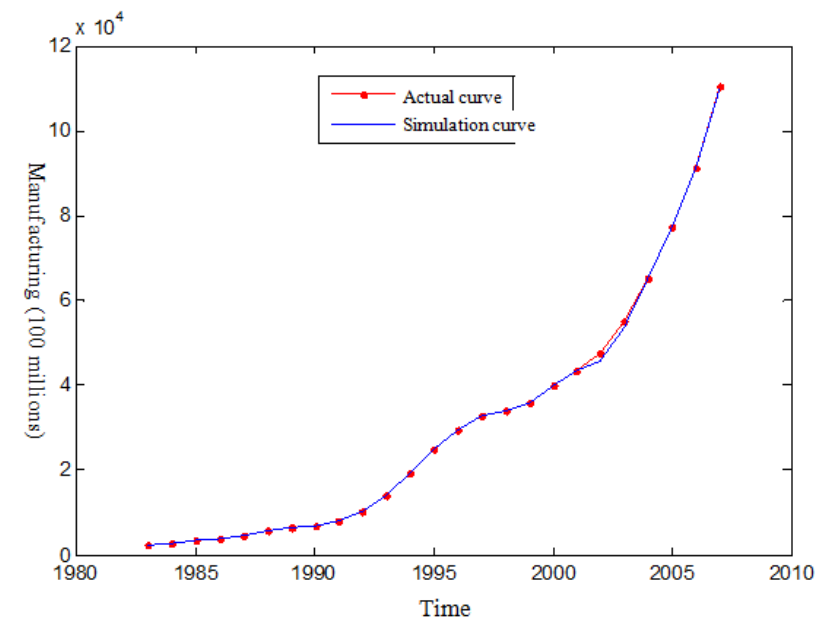

Fig.2 Dynamic evolution curves of Chinese manufacturing

\section{Acknowledgment}

The author is grateful for the support of Humanity and Social Science Youth foundation of Ministry of Education of China (14YJC790093).

\section{References :}

[1] X. Chen and J.F. Huang: China Soft Science Vol. 10 (2004), p.65

[2] M.H. Han: Advances in Intelligent and Soft Computing Vol. 106 (2011), p.249

[3] J. Gao, Y.L. Yao, C.Y. Valerie, L.Y. Sun, Linyan and L. Lin: Journal of Intelligent Manufacturing Vol. 22 (2011), p.435

[4] M. James: Journal of Systems Science and Systems Engineering Vol. 20 (2011), p.129 
[5] H.Y. Zhu, H. Wei and M.F. Zhou: Journal of Xidian University Vol. 18 (2008), p.l

[6] H. Forsman: Research Policy Vol. 40 (2011), p.739

[7] D.Y. Kong and X.Y. Xu: Economic Management Vol. 12 (2008), p.74

[8] X.P. Hu and Q.K. Li: Journal of Quantitative \& Technical Economics Vol. 2 (2009), p.33

[9] Q.R. Tang, X.J. Xu and Z.L. He: Nankai Business Review Vol. 12 (2009), p.20

[10] X.J. Xu， Q.R. Tang and Q. Fan: Management Review Vol. 23 (2011), p152 